\title{
A cryptic unstable transcript mediates transcriptional trans-silencing of the Ty1 retrotransposon in $S$. cerevisiae
}

\author{
Julia Berretta, ${ }^{1}$ Marina Pinskaya, ${ }^{1}$ and Antonin Morillon ${ }^{2}$ \\ Centre de Genetique Moleculaire-Centre National de la Recherche Scientifique (CGM-CNRS), 91198 Gif/Yvette, France
}

Cryptic unstable transcripts (CUTs) are synthesized from intra- and intergenic regions in Saccharomyces cerevisiae and are rapidly degraded by RNA surveillance pathways, but their function(s) remain(s) elusive. Here, we show that an antisense TY1 CUT, starting within the Ty1 retrotransposon and encompassing the promoter $5^{\prime}$ long terminal repeat (LTR), mediates RNA-dependent gene silencing and represses Ty1 mobility. We show that the Ty1 regulatory RNA is synthesized by RNA polymerase II, polyadenylated, and destabilized by the cytoplasmic 5' RNA degradation pathway. Moreover, the Ty1 regulatory RNA represses Ty1 transcription and transposition in trans by acting on the de novo transcribed TY1 RNA. Consistent with a transcriptional regulation mechanism, we show that RNA polymerase II occupancy is reduced on the Ty1 chromatin upon silencing, although TBP binding remains unchanged. Furthermore, the Ty1 silencing is partially mediated by histone deacetylation and requires Set1-dependent histone methylation, pointing out an analogy with heterochromatin gene silencing. Our results show the first example of an RNA-dependent gene trans-silencing mediated by epigenetic marks in $S$. cerevisiae.

[Keywords: RNA; silencing; transcription; chromatin; Set1; Xrn1]

Supplemental material is available at http://www.genesdev.org.

Received September 21, 2007; revised version accepted January 9, 2008.

Recent data have shown that cryptic unstable transcripts (CUTs) are RNA polymerase II (RNAPII)-dependent noncoding RNAs (ncRNAs) corresponding to inter- and intragenic regions of the genome and may represent $10 \%$ of intergenic transcripts in Saccharomyces cerevisiae (Wyers et al. 2005). Under normal conditions, CUTs are almost undetectable, as they are rapidly degraded by the activity of Rrp6 and Trf4, members of the nuclear exosome and the TRAMP complex, respectively (LaCava et al. 2005; Vanacova et al. 2005; Wyers et al. 2005). In addition to Trf4 and Rrp6, the cytoplasmic 5'-3' exoribonuclease Xrn1 also plays an important role in the turnover of CUTs, supporting the idea that some of these transcripts escape the nuclear quality control and might have a cytoplasmic residency (Thompson and Parker 2007).

Despite these observations, the function(s) of CUTs remain(s) poorly characterized. Cryptic transcription has been widely described from yeast to human and qualified as "transcriptional noise." Interestingly, it has been proposed that cryptic transcription allows RNA polymerase-dependent chromatin changes but not the produc-

\footnotetext{
${ }^{1}$ These authors contributed equally to this work.

${ }^{2}$ Corresponding author.

E-MAIL antonin.morillon@cgm.cnrs-gif.fr; FAX 33-1-69-82-38-77.

Article is online at http://www.genesdev.org/cgi/doi/10.1101/gad.458008.
}

tion of functional RNA molecules, as those are immediately degraded (Struhl 2007). In agreement with this model, CUT transcription has been shown to interfere with promoters of coding regions and hence regulates gene expression in S. cerevisiae (Martens et al. 2005; Hongay et al. 2006; Uhler et al. 2007). However, alternative models emerged, providing a direct function for cryptic transcripts. Indeed, recent reports have shown that the processing of siRNAs in Schizosaccharomyces pombe is mediated by homologs of the TRAMP and exosome subunits (Buhler et al. 2007; Nicolas et al. 2007), strongly indicating that the fission yeast's siRNAs might originate from CUTs. It is tempting to hypothesize that CUTs in $S$. cerevisiae are linked to an ancient mechanism that would control gene expression in an RNAdependent manner.

One of the RNAi functions is to limit mobile genetic element (MGE) proliferation in the genome (Weiner 2002). MGEs encompass viruses, transposons, and retrotransposons and are dispersed from bacteria to mammalian cells (Capy 2005). The paroxysm of mobile elements has been described in human cells whereby up to $40 \%$ of the genome is composed of repeated sequences (Lander et al. 2001) that play potentially deleterious functions in chromosome rearrangements and gene expression. Therefore, each step of the transposition cycle is tightly 
controlled. In S. cerevisiae, the Tyl retrotransposon is subjected to a cosuppression regulation (Jiang 2002) that presents similarities with the transcriptional cosuppression mediated by siRNAs in plants (Jorgensen 1995). This observation strongly suggests that a yet-uncharacterized RNAi-like mechanism might exist in budding yeast, despite the absence of the entire RNAi pathway in this organism (Aravind et al. 2000).

In this study, we address the existence of an RNAdependent gene regulation mechanism in $S$. cerevisiae. By analogy with transposon regulation in higher eukaryotes, we hypothesized that regulatory RNAs might provide the silencing signal to repress Tyl expression. With the use of strains defective for the $5^{\prime}-3^{\prime}$ and $3^{\prime}-5^{\prime}$ RNA decay pathways, we show the existence of a TY1 unstable antisense RNA that triggers Tyl transcriptional silencing in trans. We present evidence that the Tyl silencing is partially suppressed by in vivo treatment with the histone deacetylase inhibitors nicotinamide (NAM) and Trichostatin A (TSA). In addition, the Tyl silencing is controlled by the histone methyltransferase (HMT) Set 1 and the histone H3 Lys 4 methylation, providing an interesting parallel with heterochromatic gene silencing. We propose that CUTs contribute to establish a specialized chromatin domain over repetitive elements in $S$. cerevisiae to limit their dispersion.

\section{Results}

The 5'-3' exoribonuclease Xrn1 maintains Ty1 expression and mobility and destabilizes a Ty1 antisense RNA

To address the question whether regulatory RNAs can be detected within the Ty1 transposon, we analyzed, by Northern blot, TY1 RNAs in strains mutated for $5^{\prime}$ and 3' RNA decays that accumulate high levels of CUTs. Thus, total RNAs from yeast strains deleted for $X R N 1$, RRP6, TRF4, or TRF5 encoding genes were extracted, loaded on $1 \%$ agarose gel, and transferred onto a nitrocellulose membrane. A tec1s strain, deleted for a Ty1 transcription activator, was used as a control characterized by negligible levels of TY1 RNA (Laloux et al. 1994; Baur et al. 1997; Morillon et al. 2000). We probed the membrane with sense and antisense riboprobes corresponding to different regions of Ty1 (schematized in Fig. 1A) and normalized the signals with the $s c R 1$ RNA level. In the $x r n 1 \Delta$ strain, quantifications revealed a dramatic 10-fold accumulation of a $>400$-nucleotide (nt)-long antisense RNA, mapping to the 5 '-end long terminal repeat $(L T R)$ region, and that we named $R T L$ (Fig. 1B). In contrast, $\operatorname{rrp} 6 \Delta$ and $\operatorname{trf} 4 \Delta$ showed a modest twofold increase of the RTL RNA, with a slight additive effect in the $\operatorname{rrp} 6 \Delta \operatorname{trf} 4 \Delta$ strain (2.5-fold increase). It is interesting to note that the tec1 $1 \Delta x r n 1 \Delta$ strain has similar levels of the $R T L$ RNA as the $x r n 1 \Delta$ strain, suggesting that $R T L$ transcription is Tec1-independent. Remarkably, the TY1 full-length sense RNA (TY1FL) showed a fivefold decrease in the $x r n 1 \Delta$ strain, similarly to the tec1s strain (Fig. 1B). In addition, we noticed the presence of a sense-

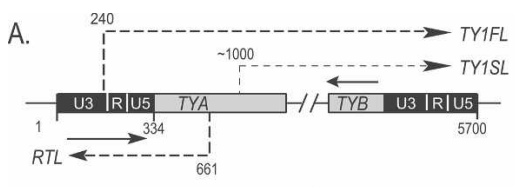

B.

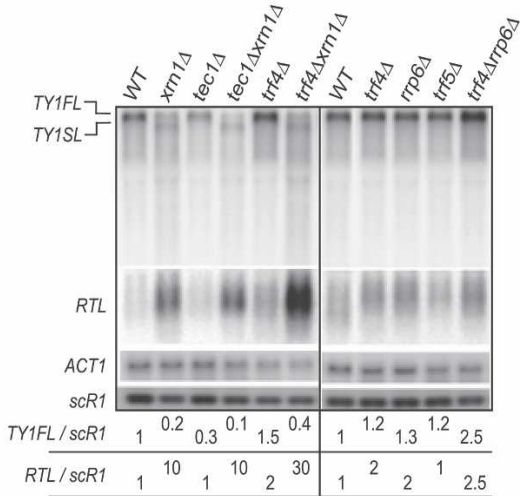

C. (ML2)TY1 :: URA3
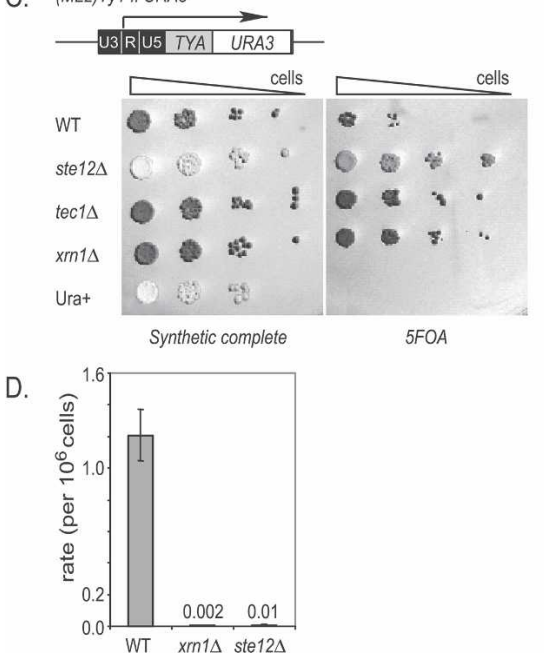

Figure 1. The $5^{\prime}-3^{\prime}$ exoribonuclease Xrnl prevents Tyl antisense RNA accumulation and maintains Tyl expression and transposition. (A) Schematization of different Tyl transcripts (dashed lines/arrows), with their respective coordinates. Positions of riboprobes specific to the RTL, TY1FL, and TY1SL RNAs are represented by solid line/arrows. Note that the probe in the TYB region hybridizes the TY1SL and TY1FL RNAs. $(B)$ Northern analysis of Tyl full-length (TY1FL), Ty1 5' shortlength (TY1SL), and 5'-LTR antisense TY1 RNA (RTL). scR1 and ACT1 were used as loading controls. Numbers represent $T Y 1 F L / s c R 1$ and $R T L / s c R 1$ RNA ratios. Strains are YAM92 (WT

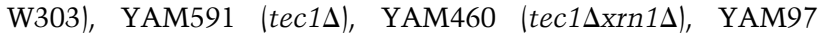

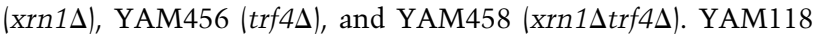
(WT BY4741), YAM125 (trf4s), YAM123 (rrp6s), YAM126

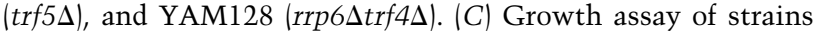
bearing TY1(ML2)::URA3 on plates containing complete synthetic media and +5FOA. The strains are YAM698 (WT),

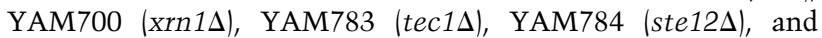
YAM166 $\left(\mathrm{ura}^{+}\right)$. (D) Transposition rate of TY1HIS3AI-containing strains, expressed as a rate of $\mathrm{HIS}^{+}$cells per total number of cells (see Materials and Methods). Strains are YAM359 (WT),

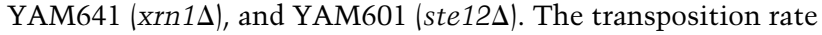
represents the mean of three independent experiments with standard deviations. 
orientated short-length Ty1 RNA (TY1SL) in the xrn1s strain. Further characterization with a probe spanning the $5^{\prime}$ end of the TYA region failed to reveal the TY1SL RNA, suggesting that TY1SL is a $5^{\prime}$-end-truncated form of the TY1FL RNA (data not shown). Interestingly, the tec $1 \Delta x r n 1 \Delta$ double mutant showed an additive decrease of the TY1FL RNA, suggesting that Xrn1 and Tec1 regulate TY1FL through two independent pathways. In contrast, TRF4, TRF5, and RRP6 deletions only resulted in slight increases of the TY1FL steady-state RNA levels. Taken together, these results show that the cytoplasmic 5 '-exonuclease Xrn1 up-regulates the TY1FL RNA but strongly represses the accumulation of two unstable TY1 RNAs: RTL and TY1SL.

To confirm the importance of Xrn 1 in Tyl expression, we constructed a strain carrying the URA3 gene in frame with the highly expressed Ty1(ML2) on chromosome XIII (Morillon et al. 2002). The expression of TY1(ML2)::URA3 was determined by assessing the resistance of cells to the 5FOA drug (see Materials and Methods). We performed a growth assay dispensing serial $10 \times$ cell dilutions of wild-type, ste $12 \Delta$, tec $1 \Delta$, and $x r n 1 \Delta$ strains carrying Ty1(ML2)::URA3, on 5FOA plates (Fig. 1C). As expected, the Ty1(ML2)::URA3 xrn1D strain was more resistant than the wild type to the 5FOA drug, similar to what is observed in strains mutated for the Ty1 transcription activators Tec1 and Ste12 (Laloux et al. 1994; Baur et al. 1997; Morillon et al. 2000). This result shows that Xrn 1 is required for the expression of a single and highly transcribed Tyl element.

Next, we aimed to test whether Xrn 1 influences Tyl mobility with the use of the Ty1HIS3(AI) strain carrying the HIS3(AI) gene inserted into a chromosomal Tyl retrotransposon (see Materials and Methods). We observed that the transposition rate of Ty1HIS3(AI) was reduced $>500$-fold in the absence of Xrn1 compared with the wild type, similar to the rate in the ste $12 \Delta$ strain (Fig. 1D), suggesting that Xrn 1 is required for Ty1 mobility.

Altogether these results show that the $5^{\prime}-3^{\prime}$ exoribonuclease Xrn1 maintains high levels of Tyl expression and transposition. In addition, Xrnl controls shorter length TY1 RNAs species, in particular the Ty1 antisense RTL RNA.

\section{RTL RNA is a CUT initiating within the Ty1 coding region}

To further characterize the RTL RNA, we extended our analysis to a wider variety of RNA decay mutants. In addition to the xrn1 $1 \Delta$ mutant, deletions of DCP1 and DCP2 genes encoding the decapping activity (Coller and Parker 2004) showed a 10-fold and fivefold increase of the RTL RNA, respectively (Fig. 2A). In contrast, RTL RNA levels were modestly increased in pat $1 \Delta, 1 s m 1 \Delta$, and $1 \sin 7 \Delta$ strains, defective for the RNA decapping enhancers (Coller and Parker 2004). Similarly, mutants defective for the No-Go-Decay (dom34s) (Doma and Parker 2006), for the nonsense-mediated decay (upf1s, upf2 $\Delta$, upf3s) (Muhlrad and Parker 1994), for the RNAdeadenylation pathway (ccr4s) (Daugeron et al. 2001), and for the endoribonuclease III RNT1 (rnt1s) (DaninKreiselman et al. 2003) showed wild-type levels of the RTL RNA. Interestingly, when comparing the levels of RTL and TY1FL RNAs, all mutants can be divided into four classes (summarized in Fig. 2B). Class I consists of cytoplasmic 5'-3' RNA decay mutants and is characterized by a large decrease of the TY1FL RNA /more than

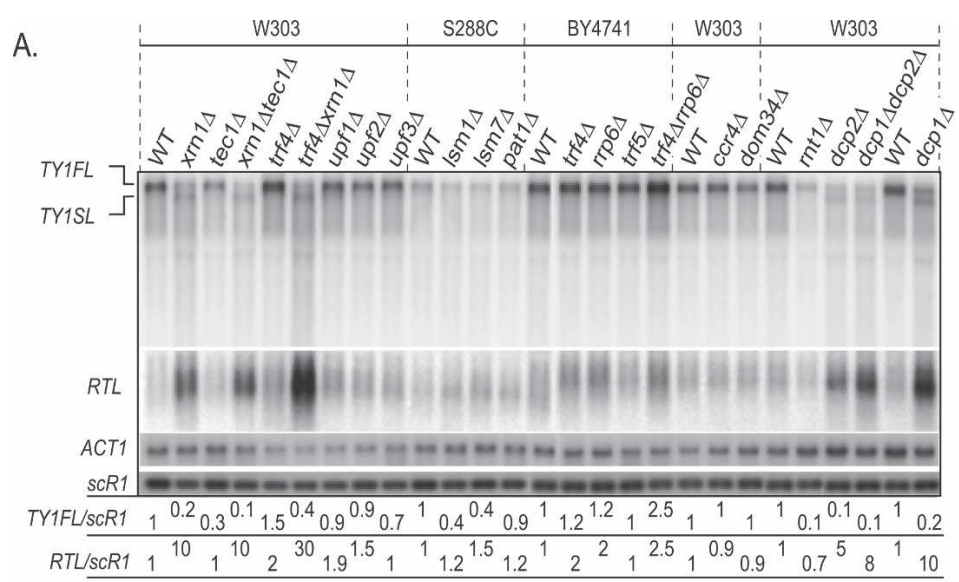

B.

\begin{tabular}{|c|c|c|c|c|}
\hline & RTL & TY1FL & mutants & function \\
\hline Class I & +++ & - & $x m 1 \Delta, d c p 1 \Delta, d c p 2 \Delta$ & 5'-3' RNA decay \\
\hline Class II & NSC & - & $|s m 1 \Delta| s m ,7 \Delta, m t 1 \Delta$ & $\begin{array}{l}\text { Decapping, enhancer, } \\
\text { processing }\end{array}$ \\
\hline Class III & + & NSC & $r r p 6 \Delta$, trf $4 \Delta$ & $\begin{array}{l}\text { 3' RNA surveillance } \\
\text { pathway }\end{array}$ \\
\hline Class IV & NSC & NSC & $\begin{array}{l}\text { upf1 } 1 \Delta, \text { upf2 } 2 \Delta \text {, upf3 } 3 \Delta, \text { pat1 } 1, \\
\text { ccr4 } 4 \text {, dom } 34 \Delta, \operatorname{trf5} \Delta\end{array}$ & $\begin{array}{l}\text { Translation related RNA } \\
\text { degradation }\end{array}$ \\
\hline
\end{tabular}

Figure 2. Effect of different RNA degradation pathways on Tyl RNAs. (A) Extended Northern analysis of transcript levels in strains bearing mutations in different RNA surveillance pathways. The membrane is identical as in Figure 1B, but mutants have been separated for presentation convenience. The probes are the same as in Figure 1B. In the left panel, the W303 strains are YAM92 (WT W303), YAM591 (tec1 1 ), YAM97

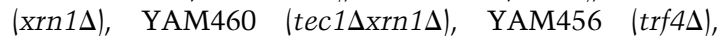
YAM458 (xrn1strf4s), YAM93 (upf1s), YAM94 (upf2s), and YAM95 (upf3s). W303 strains in the right panel are YAM92 (WT W303), YAM584 (ccr4D), YAM586 (dom34s), YAM115 (WT W303), (YAM119), YAM141 (dcp2s), YAM142 (dcp1 $d d c p 2 \Delta)$, YAM92 (WT W303), and YAM96 (dcp1 $\Delta)$. The S288C strains are YAM31 (WT S288C), YAM34 (1sm1s), YAM33 (1sm7s), and YAM32 (pat1 1 ). The BY4741 background strains are YAM118 (WT BY4741), YAM125 (trf4 $)$ ), YAM123

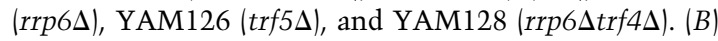
Table summarizing the effects of the four classes of mutants on Tyl RNA accumulation. RTL and TY1FL RNA changes were classified by the following rule: $(+++)$ more than fivefold increase; $(+)$ between twofold and fivefold increase; $(-)$ more than twofold decrease; (NSC) no significant change (less than twofold). 
twofold) concomitant with the appearance of high levels of RTL (more than fivefold). Class II is represented by mutants defective for decapping enhancing activities and nuclear RNA processing and that show a significant reduction of TY1FL (twofold) but without appearance of the RTL RNA (less than twofold). In contrast, class III mutants, defective in the $3^{\prime}$ nuclear surveillance pathway, have no changes in TY1FL but accumulate intermediate levels of RTL (up to fivefold). Finally, class IV is composed of mutants altered in translation-coupled RNA degradation that have very little effect on any Tyl RNAs.

According to this classification, we conclude that the cytoplasmic $5^{\prime}-3^{\prime}$ RNA decay is the main pathway controlling the RTL RNA stability but independently of translational-related and RNA deadenylation-coupled RNA decay pathways. Interestingly, the 3' RNA nuclear surveillance machinery plays a minor role in $R T L$ stability except when the $5^{\prime}-3^{\prime}$ RNA decay is strongly impaired. Finally, we noted that $R T L$ accumulation systematically correlates with the decrease of the steady-state levels of TY1FL RNA, suggesting a causal link for the fate of these two transcripts.

Ty1 RTL RNA initiates within Ty1, is synthesized by RNAPII, and degraded by Xrn1

To define more precisely the RTL RNA, we performed Rapid Amplification of CDNA Ends (5'-RACE) followed by sequencing analysis. It defined several transcription start sites in the TYA coding region with a major starting point at the +661 position from the beginning of the LTR sequence (schematized in Fig. 1A). No open reading frame was identified, suggesting that the TY1 RTL RNA is noncoding.

Furthermore, Northern blot analysis of polyadenylated $\left[\operatorname{poly}(\mathrm{A})^{+}\right]$RNAs showed that the poly $(\mathrm{A})^{+}$RTL RNA is still detectable in the $x r n 1 \Delta$ strain (Fig. 3A). Moreover, RTL/ACT1 ratios from total RNAs and poly $(\mathrm{A})^{+}$RNAs extracted from the xrn1 $1 \Delta$ strain suggest that the majority of the RTL RNA is polyadenylated (66\%) (Fig. 3A). Unexpectedly, we noted equivalent amounts of poly $(\mathrm{A})^{+}$ $R T L$ extracted from the $\operatorname{trf} 4 \Delta$ xrn $1 \Delta$ mutant $(64 \%)$. This observation suggests that the additive accumulation of the $R T L$ RNA in the $\operatorname{tr} f \Delta \Delta \times r n 1 \Delta$ mutant is not related to the Trf4-dependent poly(A) polymerization activity, consistent with previous observations showing that Trf4 has additional roles in RNA stability (Wyers et al. 2005).

Next, to confirm that the RTL RNA is produced by RNAPII, deletion of XRN1 was performed in a thermosensitive rpb1ts mutant strain (rpb1-1), mutated for RPO21, encoding the main subunit of RNAPII (see Materials and Methods). As shown in Figure 3B, after 60 min at $37^{\circ} \mathrm{C}, R T L$ was no longer visible in the xrn1 1 rpb1-1 strain (see quantification in Supplemental Fig. 1), similarly to the RNAPII-dependent RNA ACT1. In contrast, levels of the RNAPI-dependent rRNA and the RNAPIII-dependent $s c R 1$ RNA remained unchanged, suggesting that RNAPII synthesizes the RTL RNA. In addition, the relatively rapid decrease of $R T L$ levels in
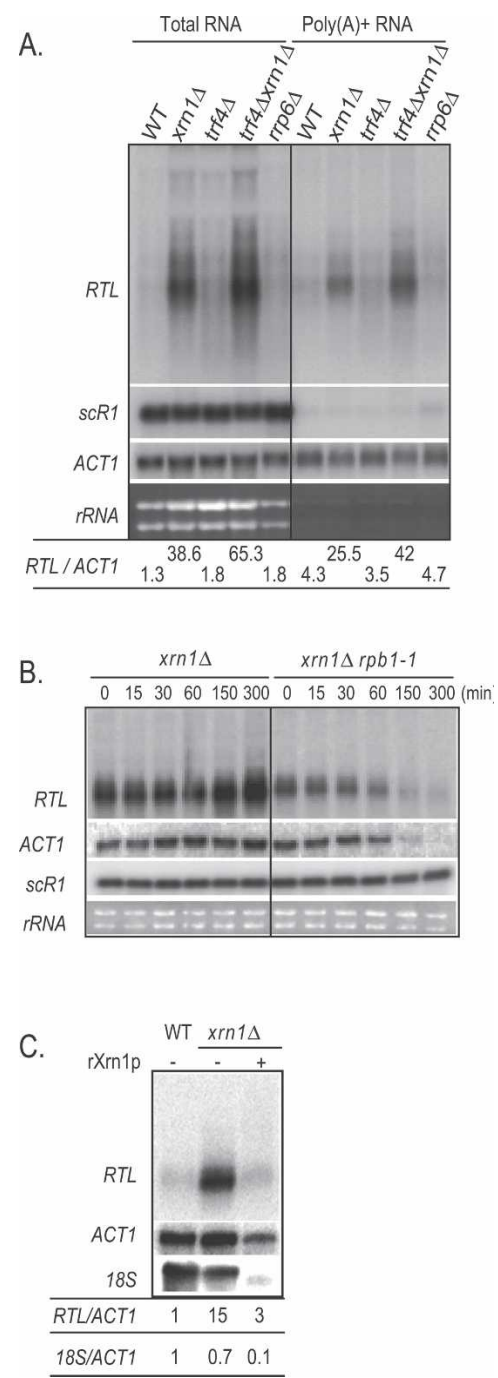

Figure 3. Characterization of the Tyl antisense RNA. $(A)$ Northern blot analysis of transcript levels in strains bearing mutations in the RNA surveillance pathways, purified on oligo(dT) beads [poly $\left(\mathrm{A}^{+}\right) \mathrm{RNA}$, right panel] or not (total RNA, left panel). The probes are the same as in Figure 1B. The strains are YAM92 (WT), YAM97 (xrn1 $\Delta)$, YAM456 (trf4s), YAM458

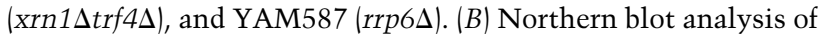
total RNA upon RNAPII inactivation. The time is in minutes after a $37^{\circ} \mathrm{C}$ heat shock. The probes are the same as in Figure $1 \mathrm{~B}$.

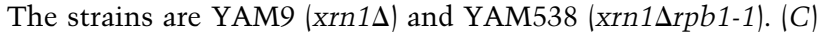
Northern blot analysis of $1 \mu \mathrm{g}$ of total RNA treated $(+)$ or not $(-)$ with $0.3 \mu \mathrm{g}$ of recombinant Xrnlp (rXrnlp). The probes are the same as in Figure 1B. The strains are YAM92 (WT) and YAM97 (xrn1s).

the $x r n 1 \Delta r p b 1-1$ strain suggests that another pathway is involved in $R T L$ degradation, consistent with an additive role of the $3^{\prime}$ nuclear surveillance pathway in $R T L$ stability.

Finally, we addressed the question whether Xrn1 directly degrades the RTL RNA or controls an activator of $R T L$ transcription. It has been shown that $\mathrm{Xrn} 1$ preferentially degrades RNA with 5' monophosphate extremity but not RNA with a capped extremity in vivo and in 
vitro (Muhlrad et al. 1995). Thus, if RTL is subjected to a Xrn1-dependent degradation in vivo, it should present an uncapped extremity when accumulating in the $x r n 1 \Delta$ strain. To test this hypothesis, we treated total RNAs extracted from the $x r n 1 \Delta$ strain with purified recombinant yeast $\mathrm{rXrn} 1 \mathrm{p}$ and analyzed the degradation profile by Northern blot (Fig. 3C). We observed that the $R T L$ RNA was degraded by $\mathrm{rXrn} 1 \mathrm{p}$ with the same efficiency as the uncapped 18S ribosomal RNA (rRNA) (fivefold and sevenfold reduction, respectively). In contrast, the capped ACT1 mRNA was resistant to rXrn1p activity. This result indicates that the $R T L$ RNA detected in the xrn1s strain is mainly uncapped, confirming that the high accumulation of the RTL RNA is a consequence of RNA stabilization and not transcriptional activation in this strain.

Taken together, our data indicate that $R T L$ is synthesized by RNAPII initiating within the Tyl coding region and polyadenylated. The Ty1 RTL RNA is then subjected to decapping followed by 5 '-3' RNA degradation performed by Xrn1. RTL destabilization is reinforced by the nuclear Trf4-dependent RNA surveillance pathway.

\section{TY1 RTL RNA controls TY1 expression in trans}

As $R T L$ accumulation coincides with down-regulation of Tyl expression, we next asked whether the RTL RNA directly controls Tyl expression and mobility. We cloned the RTL sequence under the GAL1-inducible promoter $(p G R T L)$. By switching the carbon source from glucose to galactose in the growth media, we assessed the effect of RTL overexpression on Tyl mobility. As shown in Figure 4A, the transposition rate of the Ty1HIS3(AI) element was reduced from fourfold to sevenfold in two different yeast genetic backgrounds, W303 and S288C, respectively, upon transcriptional activation of $R T L$ when compared with an empty plasmid. In contrast, upon repressive conditions in glucose, the Ty1HIS3(AI) transposition rate was identical in the strain containing the $p G R T L$ and the strain containing the empty plasmid. We conclude that the RTL RNA inhibits Tyl retrotransposition in trans.

To get insights into the minimal regulatory region(s) of $R T L$, we cloned, under the control of GAL1 promoter, $R T L$ sequences lacking the U3R ( $\left.p G R T L^{U 3 R \Delta}\right)$, the LTR $\left(p G R T L^{L T R \Delta}\right)$, and the TYA $\left(p G R T L^{T Y A \Delta}\right)$ (see Supplemental Fig. 2 for a schematic view of the truncated $R T L$ versions). Interestingly, expression of $R T L^{U 3 R \Delta}$, $R T L^{L T R \Delta}$, or $R T L^{T Y A \Delta}$ failed to fully repress (less than twofold) Tyl mobility (Fig. 4B), showing that the integrity of the RTL RNA is required to silence Tyl transposition. It is interesting to note that the minimal U3R region, corresponding to the Tyl promoter and $5^{\prime}$ untranslated region of the Ty1 RNA, is required for the Ty1 silencing, suggesting that the RTL RNA acts in trans to control transcription.

Furthermore, to test whether RTL represses a single genomic and highly expressed Tyl element, we performed a growth test assay on 5FOA plates with the Ty1(ML2)::URA3 strain transformed with the $p G R T L$ or an empty plasmid (Fig. 4C). We observed that
A.
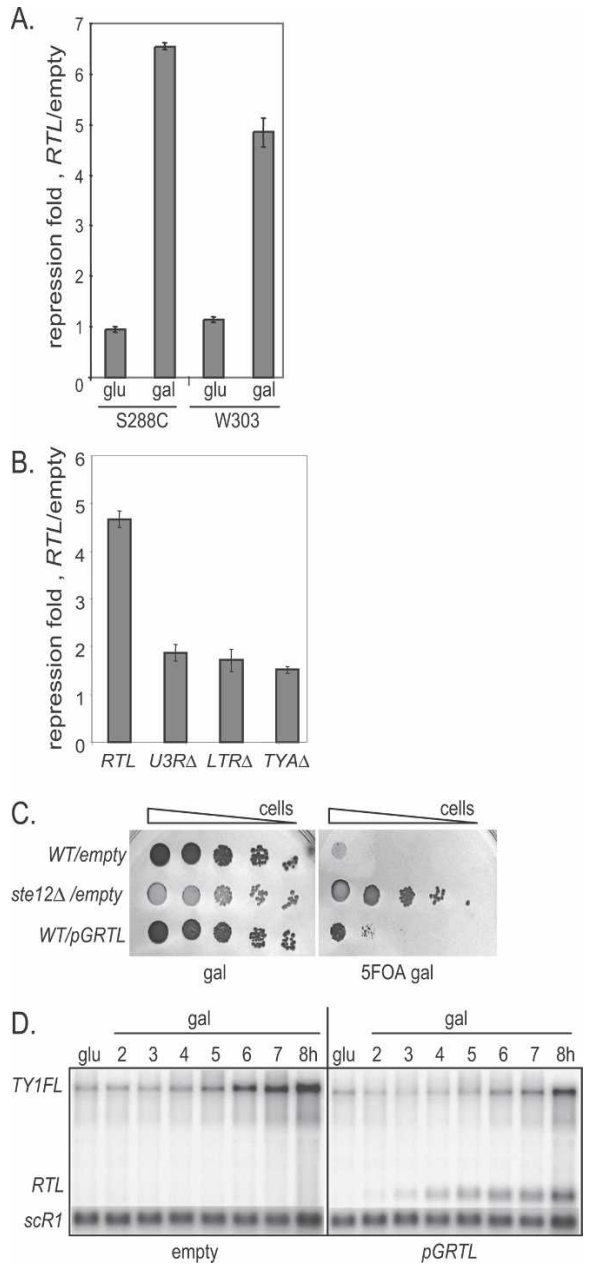

Figure 4. Trans-silencing of Tyl expression in the presence of the Ty1 RTL RNA. (A) Transposition repression fold of TY1HIS3AI strains in the presence of $p G R T L$. The repression fold is expressed as a ratio between the transposition rate measured in a strain bearing $p G R T L(p A M 134)$ and a strain bearing an empty plasmid ( $p A M 80)$ under the same growth conditions. The strains are YAM359 (S288C) and YAM358 (W303), grown in glucose (glu) or galactose (gal). The repression fold represents the mean of three independent experiments with standard deviations. (B) Transposition repression fold of TY1HIS3AI strains in the presence of truncated versions of $R T L$. The strains are the same as in $A$ but with YAM359 (WT) grown in galactose and bearing $p G R T L$ (RTL), $p G R T L^{U 3 R \Delta}$ (U3R $)$ ), $p G R T L^{L T R \Delta}$ (LTR $)$, or $p G R T L^{T Y A \Delta}$ (TYA $)$. (C) Growth ability of TY1(ML2)::URA3 strains containing $p G R T L$ (pAM167) or an empty plasmid (pAM20). Galactose plates contain complete synthetic media without leucine supplemented with 5FOA (5FOAgal) or not (gal). Cells were dropped after serial 10× dilutions. The strains are YAM698 (WT) and YAM784 (ste12A). (D) Northern blot analysis of total RNAs in a $P_{\text {GAL1 }}$ ste12 strain (YAM799) bearing $p G R T L$ ( $p A M 134$ ) or an empty plasmid ( $p A M 80)$. The probes are the same as in Figure 1B. The time is in hours of growth in galactose.

Ty1(ML2):: URA3 strain grew better on $5 \mathrm{FOA}^{+}$galactose plates in the presence of $p G R T L$ when compared with the TY1(ML2)::URA3 strain containing an empty 
plasmid, but with a lower efficiency than a Ty1(ML2)::URA3 ste12s strain, fully 5FOA-resistant. This result confirms that $R T L$ down-regulates the highly expressed Ty1(ML2) in trans by controlling Ty1 expression at transcriptional or/and post-transcriptional steps.

Finally, to kinetically monitor $R T L$-dependent repression on the newly synthesized TY1 RNA, we designed a $P_{\text {GAL1 }}$ ste 12 strain containing the STE12 gene, encoding the Tyl transcription activator, under the control of the GAL1 promoter. The $P_{G A L 1}$ ste 12 strain was transformed with the $p G R T L$ plasmid or an empty vector. In glucosecontaining medium, repressing STE12 transcription, we observed very low levels of the TY1FL RNA, confirming that STE12 is required for Ty1 transcription (Fig. 4D, first lane in left panel). As expected, upon shift to galactose-containing media and in the presence of the empty vector, we observed progressive increase of the TY1FL RNA levels (Fig. 4D, left panel; see quantification in Supplemental Fig. 3). In contrast, coexpression of RTL impaired the Ste12-dependent TY1 activation, suggesting that the RTL RNA represses the accumulation of neo-synthesized TY1 RNA (Fig. 4D, right panel; see quantification in Supplemental Fig. 3).

Altogether, these results strongly suggest that the $R T L$ RNA silences the Ty1 expression in trans through an RNA-dependent mechanism acting on the de novo synthesized TY1 RNA.

\section{Xrn1 controls Ty1 expression at a post-TBP recruitment step}

In an attempt to define the RNA-dependent regulatory mechanism that controls Ty1 expression, we performed chromatin immunoprecipitation (ChIP) on formaldehyde-cross-linked cells and recovered the coimmunoprecipitated DNA. The DNA was subjected to real-time PCR by using Tyl-specific probes (schematized on Fig. $5 \mathrm{~A})$ to measure changes in the relative occupancy of chromatin-associated factors. When immunoprecipitating Rpb1, the largest subunit of RNAPII, we found that RNAPII occupancy decreased from twofold to threefold within the Ty1 elements in xrn1s and ste $12 \Delta$ strains when compared with the wild type (Fig. 5B). In contrast, the unrelated constitutive POL1 gene showed equivalent levels of RNAPII occupancy in wild-type, xrn1s, and ste $12 \Delta$ strains (Supplemental Fig. 4), strongly suggesting that, in the xrn1s strain, Tyl transcription is severely impaired and reaches background levels observed in the ste $12 \Delta$ strain.

The transcription process is controlled at the level of initiation, elongation, and termination (Svejstrup 2004). To discriminate which transcription step is controlled upon Tyl silencing, we performed ChIP experiments using wild-type and $x r n 1 \Delta$ strains carrying the HA-tagged TBP, which is associated with the preinitiation complex for RNAPII-dependent regulation (Kuras and Struhl 1999). Remarkably, TBP occupancy was not significantly affected in $x r n 1 \Delta$ and ste $12 \Delta$ strains (Fig. 5C), suggesting that TBP recruitment on the Ty1 promoter is not a limiting step when Tyl is silenced.
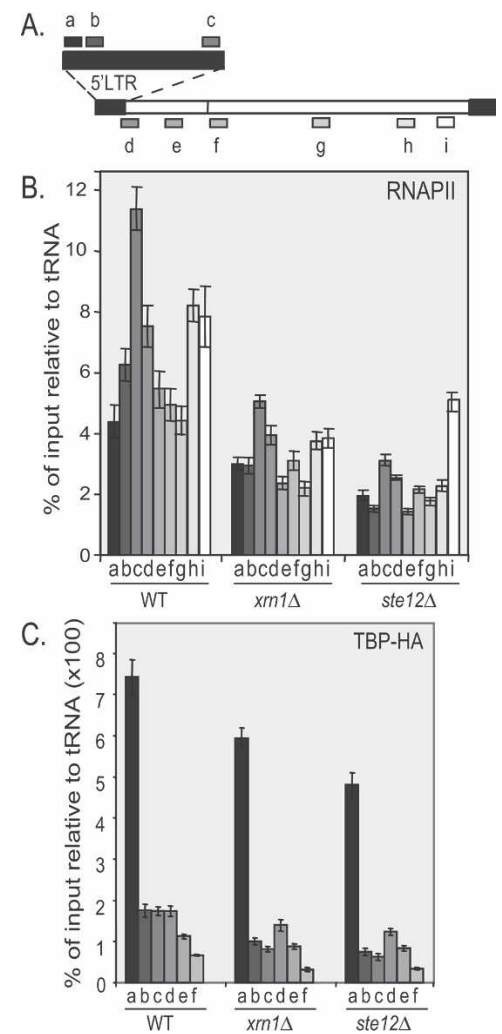

Figure 5. Xrn 1 controls Tyl transcription initiation at a postTBP recruitment step. (A) Positions of different Tyl amplicons on the Tyl chromatin for real-time PCR analysis. (B) Real-time PCR quantification of RNAPII using primers over Tyl chromatin. Percentage of immunoprecipitation signals relative to input, normalized with the $t R N A$ region. The strains are YAM198

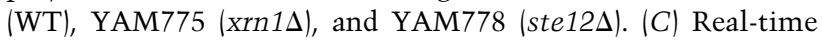
PCR quantification of HA-TBP using primers over Tyl chromatin. The same normalization as in $B$. The strains are YAM208

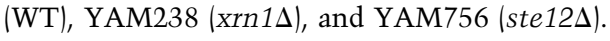

Altogether, our results suggest that the RTL RNA promotes Tyl gene silencing through a transcriptional mechanism occurring after TBP recruitment.

\section{Histone deacetylation and HMT Set1 mediate Ty1 gene silencing}

Gene silencing is a key feature of heterochromatin domains and is marked by epigenetic signals such as histone $\mathrm{H} 3$ and $\mathrm{H} 4$ lysine deacetylation. In addition, HMT Dot1 and Set1 controlling H3K79me and H3K4me, respectively, create a boundary between euchromatin and heterochromatin through a mechanism that might restrict localization of the silencing regulators Sir3 and/or Sir2 (van Leeuwen et al. 2002; Santos-Rosa et al. 2004). To test whether the Ty1 silencing mechanism involves heterochromatin regulators, we first treated wild-type and $x r n 1 \Delta$ strains with histone deacetylase inhibitors NAM and TSA, repressing nicotinamide adenine dinucleotide (NAD)-dependent and class I or II histone deacetylases, respectively (Bernstein et al. 2000; Bitter- 
man et al. 2002). Cells treated with 5 mM NAM or 10 $\mu \mathrm{M}$ TSA were harvested at different time points to extract total RNAs. Northern blot analysis (Fig. 6A) showed that, in the xrn1 $1 \Delta$ strain, the TY1FL RNA levels increased up to threefold after $240 \mathrm{~min}$ of NAM treatment (see quantification in Supplemental Fig. 5A). In addition, TSA treatment showed a dramatic eightfold increase of the TY1FL levels in the xrn1D strain after 240 min (see quantification in Supplemental Fig. 5B). Furthermore, we noted that the RTL RNA levels were twofold decreased upon NAM treatment (see quantification in Supplemental Fig. 5C), suggesting that a NAD-dependent histone deacetylase(s) mediate(s) the Tyl silencing, putatively by controlling the $R T L$ accumulation. In contrast, upon TSA treatment, the RTL levels increased up to twofold (see quantification in Supplemental Fig. 5C), strongly supporting that a class I or a class II histone deacetylase controls the Tyl silencing at a step following
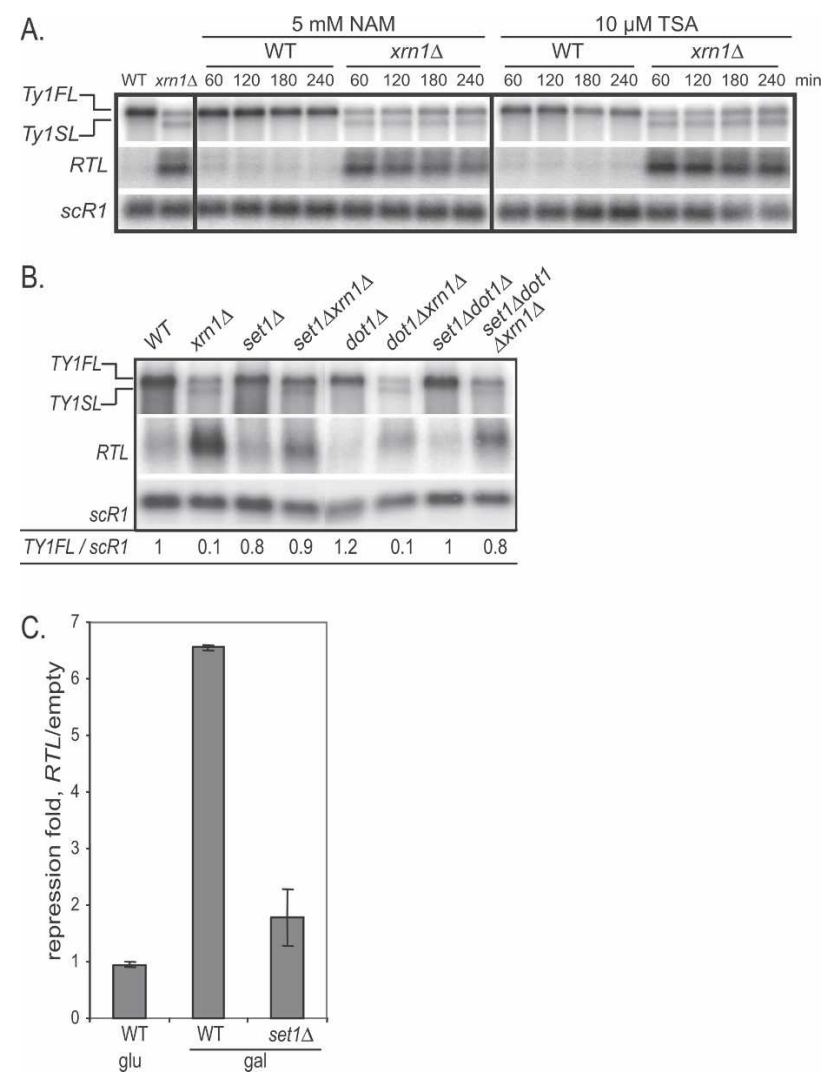

Figure 6. Histone deacetylation and HMT Set1 mediate Tyl silencing. (A) Northern blot analysis of total RNAs in the presence of histone deacetylase inhibitors. The probes are the same as in Figure 1B. The strains YAM250 (WT) and YAM97 (xrn1A) were treated with $5 \mathrm{mM}$ NAM or $10 \mu \mathrm{M}$ TSA, and cells were collected at the indicated time points. $(B)$ Northern analysis of total RNAs. The probes are the same as in Figure 1B. The strains

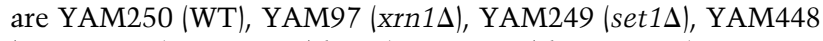

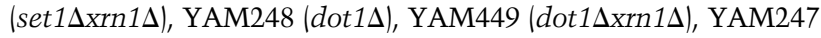
$(\operatorname{set} 1 \Delta \operatorname{dot} 1 \Delta)$, and YAM444 $(\operatorname{set} 1 \Delta \operatorname{dot} 1 \Delta \mathrm{xrn} 1 \Delta) .(C)$ Repression fold of transposition rates of TY1HIS3AI strains bearing the pGRTL and empty plasmids. The strains are YAM359 (WT) and YAM702 $(\operatorname{set} 1 \Delta)$. The same conditions as in Figure 4A.
$R T L$ expression. This analysis suggests that deacetylation of histones is a key regulation step of Tyl silencing.

Next, to further determine whether Tyl silencing resembles heterochromatin silencing, set1 $\Delta$ and $\operatorname{dot} 1 \Delta$ mutants were combined with XRN1 deletion, and total RNAs were probed for TY1FL and RTL RNAs (Fig. 6B). We observed that, in $\operatorname{dot} 1 \Delta x r n 1 \Delta$, the TY1FL remained at the same level as in the $x r n 1 \Delta$ strain (Fig. 6B). In contrast, a null allele of SET1 inserted in the xrn1 $1 \Delta$ strain restored wild-type TY1FL levels, strongly suggesting that Set1 is required to silence Tyl. However, as with the NAM treatment, we observed a slight decrease of $R T L$ in set $1 \Delta$ xrn $1 \Delta$ compared with the xrn $1 \Delta$ strain, suggesting that the TY1FL derepression might be due to the decrease of the RTL RNA levels.

To further test the role of Set1 in Ty1 silencing, we asked whether Set1 controls the RTL-dependent silencing in trans. The SET1 gene was deleted in the strain containing the Ty1HIS3(AI) to measure the Tyl mobility in the presence of $p G R T L$ upon galactose induction. As shown in Figure 6C, the set1s strain containing the $p G R T L$ showed a modest twofold repression of the Tyl transposition rate when compared with the sevenfold repression in wild type. As the set $1 \Delta$ strain showed mild change in the $p G R T L$ induction (data not shown), we conclude that RTL mainly represses the Ty1 expression via Set1.

Taken together, these results show that Tyl silencing is mediated by epigenetic signals established by Set 1 and histone deacetylases and presents strong similarities with heterochromatin silencing.

\section{Ty1 silencing is controlled by H3K4me}

To get further insights into the Tyl silencing mechanism, we investigated the role of Set1 activity on Tyl expression. The HMT Set1 catalyzes the addition of one, two, or three methyl groups on the H3K4 (H3K4me1, H3K4me2, and H3K4me3, respectively) and plays multiple roles in DNA repair, transcription, and heterochromatin regulation (Dehe and Geli 2006). In addition, H2B ubiquitylation on Lys 123 (H2BK123-Ub) is required for $\mathrm{H} 3 \mathrm{~K} 4 \mathrm{me} 2$ and $\mathrm{H} 3 \mathrm{~K} 4 \mathrm{me} 3$, but not for tethering Set 1 on chromatin (Sun and Allis 2002; Dehe et al. 2005; Shahbazian et al. 2005).

As Set 1 is required for Tyl silencing, we first tested, by ChIP experiments, whether H3K4me1, H3K4me2, or H3K4me3 would change on Tyl chromatin upon Tyl silencing. Interestingly, the methylation states of H3K4 showed no difference in the xrn1s and wild-type strains (data not shown), suggesting that H3K4 methylation marks have an indirect or transient effect on Tyl silencing. Alternatively, Set1 might control Ty1 silencing in a histone-independent manner.

To discriminate between these two possibilities, we asked whether H3K4 methylation is required for the Ty1 silencing. We performed Northern blot analysis with RNAs extracted from strains bearing point mutations at $\mathrm{H} 3$ Lys 4 . As a control, we used a mutation at $\mathrm{H} 3$ Lys 79, targeted by the HMT Dot1. As expected, the 
H3K79Axrn1 $1 \Delta$ mutant had similar TY1FL RNA levels as $x r n 1 \Delta$, confirming that Dot 1 catalytic activity is not involved in the Tyl silencing mechanism (Fig. 7A). In contrast, the H3K4A mutant, preventing Set1-dependent H3K4 methylation, showed wild-type levels of TY1FL RNAs when combined with the xrn $1 \Delta$ mutant, supporting the idea that H3K4 methylation promotes Tyl silencing in the strain lacking Xrn1. In addition, we noted that the H3K4A mutant showed higher levels of the
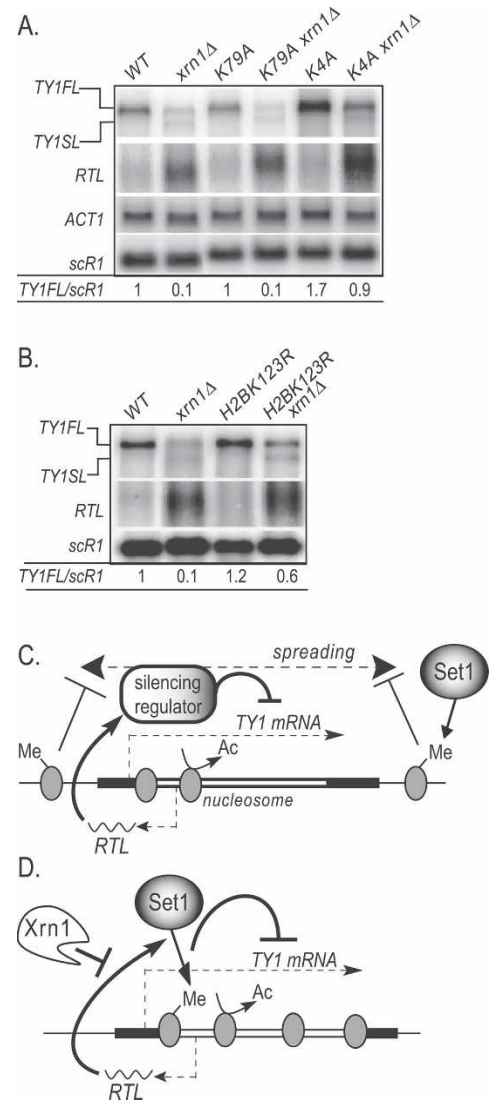

Figure 7. H3K4me controls Ty1 silencing. (A) Northern blot analysis of total RNAs. The probes are the same as in Figure 1B. The strains are YAM212 (WT), YAM762 (xrn1D), YAM216 (H3K4A), YAM764 (H3K4Axrn1A), YAM214 (H3K79A), and YAM673 (H3K79Axrn1D). (B) Northern blot analysis of total RNAs. The probes are the same as in Figure 1B. The strains are YAM166 (WT), YAM167 (xrn1s), YAM835 (H2BK123R), and YAM836 (H2BK123Rxrn1D). (C) Model of RNA-dependent Ty1 transcriptional gene silencing indirectly controlled by Set1. If not destabilized by the cytoplasmic exonuclease Xrn1, the RTL RNA targets an unknown silencing factor that inhibits Tyl transcription through histone deacetylation. Furthermore, the silencing factor is restricted on Tyl chromatin by Set1-dependent histone methylation, as suggested for heterochromatic domains. In the absence of Set1, the silencing factor spreads on adjacent chromatin, allowing Tyl transcription to be derepressed. $(D)$ Model of RNA-dependent Tyl transcriptional gene silencing directly controlled by Set1. Same as in $C$ but the $R T L$ RNA activates Set1-dependent histone methylation on Tyl embedded nucleosomes. Histone methylation is then recognized by a putative silencing factor that represses Tyl transcription through histone deacetylation.
TY1FL RNA than the wild type, in contrast to the set1D strain (Fig. 6B). This observation suggests that Lys 4 on histone $\mathrm{H} 3$ has a residual repressive activity on Ty1 expression even when it is unmethylated.

To confirm that Set1 has a histone methylation-dependent activity in Ty1 silencing, we analyzed Ty1 RNA levels in a H2BK123R strain controlling the histone-dependent Set1 activity without impairing its chromatin recruitment. Thus, we combined xrn $1 \Delta$ and $H 2 B K 123 R$ mutations and performed a Northern blot analysis (Fig. 7B). Our result showed that the TY1FL RNA level was sixfold increased in H2BK123Rxrn1s strain compared with $x r n 1 \Delta$, suggesting that H2BK123-dependent histone methylation controls Tyl silencing. Furthermore, as the $H 2 B K 123 R$ strain is only devoid of $\mathrm{H} 3 \mathrm{~K} 4 \mathrm{me} 2$ and $\mathrm{H} 3 \mathrm{~K} 4 \mathrm{me} 3$, we propose that Ty1 silencing is mediated by H3K4me2 and/or H3K4me3.

These data support the idea that Set1 controls Ty1 silencing through its histone methylation activity, directly or indirectly.

\section{Discussion}

Our results support the existence of an RNA-dependent gene regulation mechanism in $S$. cerevisiae controlling the Ty1 retrotransposon transcription and mobility. This regulation is mediated by an antisense TY1 RNA, initiating within the TYA region and encompassing the $5^{\prime}$ LTR domain, and necessitates histone deacetylation and Set1-dependent histone methylation, two important epigenetic features of heterochromatin domains. Importantly, the Tyl silencing is antagonized by the cytoplasmic 5' -3 ' exonuclease Xrn 1 that prevents accumulation of the cryptic regulatory RNA.

\section{Identification of a novel CUT}

In this study, we characterized a novel CUT not identified previously, as repeated sequences were eliminated from the microarray analysis (Wyers et al. 2005). CUTs were shown to accumulate when RNA surveillance pathways are defective, in particular when the Rrp6 component of the exosome is inactive (Wyers et al. 2005). Some CUTs escape the nuclear surveillance pathway but are degraded by the cytoplasmic $5^{\prime}-3^{\prime}$ decay (Thompson and Parker 2007). This is the case of the Ty1 RTL CUT, identified in this study, which is not subjected to the nuclear surveillance pathway but is very sensitive to the activity of the $5^{\prime}-3^{\prime}$ decay factors Xrn1, Dcp1 and Dcp2. The nuclear Xrn1-homolog Rat1 has a very modest impact on $R T L$ stability (data not shown), suggesting that $R T L$ processing and degradation are mainly cytoplasmic. The deadenylation coupling RNA degradation factors Ccr4, Pat1, and Lsm proteins have a minor effect on $R T L$ stability, suggesting that RTL might be processed and degraded independently of its poly(A) tail. However, in the absence of the cytoplasmic $5^{\prime}-3^{\prime}$ RNA degradation pathway, Trf4 plays an important role in the RTL destabilization process as we noted an addi- 
tive accumulation of the RTL RNA in $x r n 1 \Delta \operatorname{tr} 44 \Delta$, implying that these two pathways communicate with each other despite functioning in two different compartments of the cell.

\section{CUTs mediate gene regulation}

The function of CUTs remains elusive, but cryptic transcription was proposed to mediate chromatin changes controlling promoter activity and gene expression. In $S$. cerevisiae, several examples have already been described, and the current model proposes that the CUT transcription interferes with the gene transcription (Martens et al. 2005; Hongay et al. 2006; Uhler et al. 2007). This model implies that the RNA molecule itself has a minor function as being immediately degraded by the nuclear surveillance pathway in normal conditions. Our data show that $R T L$ silences Tyl expression in trans by acting on the de novo synthesized TY1 RNA. Furthermore, attempts to define a minimalist Tyl regulatory RNA showed that the TYA and U3/R regions are required for Tyl silencing, suggesting that the integrity of the regulatory RNA is important. Consistent with this observation, we failed so far to detect shorter, processed regulatory TY1 RNAs that could be involved in the Ty1 silencing in vivo. To our knowledge, this is the first example of RNA-dependent gene trans-silencing in S. cerevisiae.

\section{Transcriptional gene silencing}

Gene trans-silencing has been well characterized in plants and mammalian cells, where it mainly acts at a post-transcriptional level, controlling cognate mRNA translation or degradation. Here, we show that the Tyl trans-silencing affects transcription at early steps. Indeed, two lines of evidence support a transcriptional gene silencing model. First, Tyl silencing is characterized by a significant reduction of RNAPII occupancy over the Ty1 chromatin, which might lead to a large decrease in Tyl expression and mobility. Furthermore, we show that histone deacetylation and Set1-dependent histone methylation control Ty1 repression, suggesting that Tyl silencing is a nuclear event occurring at the chromatin level.

However, we cannot rule out the possibility that Ty1 is silenced additionally at post-transcriptional step(s). This idea is reinforced by the large difference in the transposition repression fold observed in the xrn1s strain (500-fold) and in a strain in which RTL transcription is induced from a plasmid (sevenfold in presence of $p G R T L)$. This observation suggests that Xrnl either destabilizes other Tyl regulatory RNAs or controls posttranscriptional steps during the transposition cycle. For instance, previous studies revealed a structural role of Xrn1 and P-body components in the assembly of gypsylike Ty3 VLPs (Beliakova-Bethell et al. 2006). One could hypothesize that this function is conserved for the assembly process of Tyl VLPs as well. This defect would add up to the transcriptional defect we observed in the xrn $1 \Delta$ strain and would provide an explanation for the low transposition rate in this mutant.

The transcriptional silencing model implies that the regulatory TY1 RNA shuttles back to the nucleus. This dynamic model is supported by very few examples in $S$. cerevisiae. For instance, only some tRNAs have been shown to cycle back to the nucleus after delivering their amino acids under stress conditions (Dahlberg and Lund 2005). Alternatively, we can hypothesize that the Tyl regulatory RNA is retained and processed in the nucleus, despite Xrn 1 and Dcp $1 / 2$ proteins being mainly cytoplasmic. In support of this idea, decapping activity was shown to occur in the nucleus when mRNA export was blocked (Kufel et al. 2004). Further experiments on localization of the Tyl regulatory RNA will provide insights into mechanisms of the Tyl silencing as well as RNA transport.

\section{Chromatin-mediated gene silencing}

Ty1 silencing is mediated by epigenetic signals that control heterochromatin domains. In particular, we showed that the Set1-dependent histone methylation has a crucial role. Set1 has been extensively characterized over the last 5 years (Dehe and Geli 2006). It is part of the eight-subunit SET1C complex that mono-, di-, and trimethylates histone $\mathrm{H} 3$ and nonhistone proteins (Roguev et al. 2001; Zhang et al. 2005). H3K4me3 is a mark of active genes, but, surprisingly, no major transcription defect has been linked with the absence of H3K4me3 (Santos-Rosa et al. 2002). Originally, Set1 was characterized to establish subtelomeric HM and rDNA silencing (Nislow et al. 1997). Current models propose that H3K4 methylation restricts silencing factors such as Sir3 to telomeric regions (Santos-Rosa et al. 2004). Indeed, in the absence of Set1, Sir3 spreads into the euchromatin, fading the silencing at the heterochromatin loci. Similarly to heterochromatin silencing, we present evidence that Set 1 and $\mathrm{H} 3 \mathrm{~K} 4 \mathrm{me} 2$ and/or H3K4me3 are also involved in Ty1 silencing. Two alternative models of Ty1 silencing can be proposed.

By analogy with heterochromatin, Set1-dependent H3K4 methylation, flanking the transposon, might restrict a Tyl putative silencing factor on the transposon. The absence of Set1 and H3K4 methylation would release the silencing factor from the Tyl chromatin and derepress the Tyl expression (see model in Fig. 7C). As in heterochromatin domains, histone deacetylases would deacetylate Tyl chromatin and contribute to Tyl silencing. In favor of this model for an indirect role of Set1, no change in H3K4 methylation was observed on Ty1 chromatin upon silencing (data not shown).

The second model is based on a direct role of histone H3K4 methylation in Tyl silencing. The RTL regulatory RNA could transiently target or activate Set1, allowing temporally H3K4 methylation of the Ty1 chromatin that might be subsequently recognized by a specific silencing regulator (see model in Fig. 7D). As for the previous model, histone deacetylation would reinforce the Tyl 
silencing. Despite the fact that H3K4me3 and H3K4me2 are marks of actively transcribed chromatin, recent data suggest that they might also have inhibitory effects as well. Indeed, chromatin repressing factors, such as histone deacetylase complexes, were shown to bind directly to the trimethylated $\mathrm{H} 3 \mathrm{~K} 4$ via the plant homeodomain (PHD) (Mellor 2006; Sims and Reinberg 2006). Moreover, upon silencing induction, $\mathrm{H} 3 \mathrm{~K} 4$ has been shown to be transiently mono- or dimethylated on the silenced HM regions in $S$. cerevisiae, revealing a putative direct role of these marks during heterochromatin formation (KatanKhaykovich and Struhl 2005).

Interestingly, both models involve histone deacetylation. In S. cerevisiae, heterochromatin establishment and maintenance is mainly regulated by the NAD-dependent histone deacetylase Sir2 (Shore et al. 1984), but also by class I and II histone deacetylases (Rundlett et al. 1996). Further investigation will allow us to determine the histone substrate and histone deacetylase(s) involved in Tyl silencing (Hickman and Rusche 2007).

\section{Ancient form of RNA-dependent gene silencing}

Long or short regulatory RNAs have been widely described in prokaryotes and eukaryotes to control gene expression. Following our observations, several similarities between eukaryotic RNA-dependent gene silencing and the $R T L$-dependent Tyl silencing can be drawn.

Long ncRNAs control gene expression and can initiate chromatin modifications on specific regions. Xist ncRNA and the Hox antisense ncRNAs (HOTAIR RNA) silence the entire $\mathrm{X}$ chromosome and the $H O X$ genes' expression, respectively (Masui and Heard 2006; Rinn et al. 2007). The relationships between the Xist RNA and chromatin modifications are still poorly characterized. But recently, the HOTAIR regulatory RNA was shown to directly interact with the HMT PRC2 to tether and induce histone H3K27 methylation over the Hox locus and hence to control, in trans, gene expression and chromatin organization (Rinn et al. 2007). This direct interaction between a regulatory RNA and a chromatin modifier is fundamental and provides an important step to understand targeted chromatin modifications. Our results show that Set1 is involved in the RNA-dependent Ty1 silencing, and one could speculate that the RTL long ncRNA would directly interact with Set 1 protein, targeting its activity to the Tyl chromatin for silencing.

Concerning short regulating RNAs, we could not provide any data that support a Tyl silencing mechanism mediated by siRNAs. Nevertheless, it is interesting to note that two genetic screens in Caenorhabditis elegans showed that the Set1 homolog regulates transposon silencing in an RNAi-dependent manner, through a mechanism that could be similar to the Set1-mediated Ty1 silencing described in this study (Grishok et al. 2005; Robert et al. 2005). More strikingly, in rat testis, small regulatory RNAs, such as rasiRNAs and piRNAs, were recently found to control transposable element transcription (O'Donnell and Boeke 2007). Interestingly, these RNAs were proposed to originate from long anti- sense ncRNA (Vagin et al. 2006) that could resemble the RTL RNA regulating Tyl expression. Although most of the RNAi features are absent in $S$. cerevisiae, our work might have uncovered a primitive and ancestral pathway of RNA-dependent gene regulation.

\section{Materials and methods}

\section{Yeast strains and plasmid construction}

The strains used in this study are described in Supplemental Table 1 . The experiments were mostly performed in the W303 background. Gene deletions and epitope tags were introduced by transformation of PCR fragments generated with specific primers (sequences can be obtained upon request) using the appropriate plasmids listed in Supplemental Table 2 (Longtine et al. 1998).

The yeast strain carrying $M L 2:: U R A 3$ is a derivative of W303 in which we introduced $U R A 3$ in frame with TYA(ML2) by single-step recombination. The recombination sites correspond to TYA(967-1007) and to a region located downstream from Ty1(ML2) (chrXIII coordinates 202532-202571) resulting in the deletion of the TYB(ML2) region. Plasmid $p A M 134$ is a derivative of $p A M 80$ (pYESdest52; Invitrogen) in which we introduced the Ty1 sequence amplified by PCR from $p A M 22$ (661-1 nucleotides) following the manufacturer's instructions. Similarly, partially truncated $R T L$ sequences were cloned to produce $p A M 182$ (U3RA, 661-290, pGRTL $\left.{ }^{U 3 R}\right)$ ) pAM184 (TYAL, 334-1, pGRTL $\left.{ }^{T Y A \Delta}\right)$, and $p A M 183\left(L T R \Delta, 661-334, p G R T L^{L T R \Delta}\right)$. Ty1 sequences were amplified by PCR from $p A M 3$. pAM167 is a derivative of $p A M 134$ with LEU2 instead of URA3. All constructs were subsequently sequenced.

\section{Media and culture conditions}

Growth media and plates were prepared with standard methods using YPDA and CSM media (Gibco) supplemented as indicated and containing $2 \%$ glucose or $2 \%$ galactose. 5 FOA experiments were carried out as follows: Transformed yeast cells were grown on appropriate selective media and were dropped on selective CSM plates containing $1 \mathrm{mg} / \mathrm{mL} 5 F O A$ (Melford laboratory). Histone deacetylase inhibitors were added to YPDA media at 5 $\mathrm{mM}$ for NAM (Sigma) and $10 \mu \mathrm{M}$ for TSA (Sigma).

\section{RNA extraction, $\operatorname{poly}(A)^{+}$RNA purification, and Northern blotting}

Total RNA was extracted using the hot phenol extraction procedure. Poly(A) ${ }^{+}$RNAs were purified on oligo(dT) Dynabeads (Invitrogen). Otherwise stated, $5 \mu \mathrm{g}$ of total or poly(A) ${ }^{+}$RNAs were loaded on denaturing $1 \%$ agarose gel and transferred to nitrocellulose membranes. Membranes were UV-cross-linked and hybridized overnight at $65^{\circ} \mathrm{C}$ with either ${ }^{32} \mathrm{P}$-labeled DNA probes or single-stranded riboprobes in Ultrahyb buffer (Sigma). Blots were washed twice with $0.5 \times$ SSC and $1 \%$ SDS for $20 \mathrm{~min}$ at $65^{\circ} \mathrm{C}$. DNA probes were obtained by random-primed labeling (Stratagene) of specific DNA fragments generated by PCR. Single-stranded riboprobes were obtained by SP6 in vitro transcription of gene-specific PCR fragments containing the SP6 promoter (Ambion). PCR primers are available upon request. $A C T 1$ and $s c R 1$ RNAs were used as loading controls.

\section{Transposition test}

In the TylHIS3AI strain, HIS3 was inserted in the TYB region of a Tyl element in the antisense orientation /Curcio and Garfinkel 1991). HIS3 RNA synthesis was independent of the 
Tyl transcription but was interrupted by an artificial intron only spliced during TY1 RNA transcription. The colony became HIS $^{+}$when the Ty1HIS3(AI) transposed resulting in a newly inserted Ty1HIS3 with a functional HIS3 gene. Thus, the transposition rate corresponded to the number of $\mathrm{HIS}^{+}$over the total number of colonies. Three independent cultures of strains-

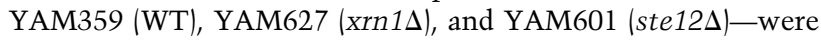
grown in YPDA overnight at $30^{\circ} \mathrm{C}$. Cells were diluted 1:100 in YPDA media and grown $48 \mathrm{~h}$ at $20^{\circ} \mathrm{C}$. An equal volume of $2 \times$ YPDA broth was added, and cultures were grown for an additional $24 \mathrm{~h}$ at $20^{\circ} \mathrm{C}$. Aliquots of each culture were plated on YPDA and CSM-HIS plates and incubated during $3-4 \mathrm{~d}$ at $30^{\circ} \mathrm{C}$. The rate of Tylhis $3 A I$ transposition is the number of $\mathrm{His}^{+}$colonies divided by the total number of colonies plated (on YPDA plates) (Curcio and Garfinkel 1991).

In the trans-silencing transposition assay with $R T L$-dependent repression, three independent transformants of plasmids pAM80 or pAM134 in strains YAM359 (S288C) and YAM358 (W303) were grown in CSM-Ura $2 \%$ glucose broth at $30^{\circ} \mathrm{C}$. Cells were diluted 1:100 in CSM-Ura $2 \%$ galactose broth and grown for $48 \mathrm{~h}$ at $20^{\circ} \mathrm{C}$. Glucose was added to reach $2 \%$ final, and cells were grown for an additional $24 \mathrm{~h}$ at $20^{\circ} \mathrm{C}$. Aliquots of each culture were plated on CSM-Ura $2 \%$ glucose agar and CSM-UraHis $2 \%$ glucose agar and incubated at $30^{\circ} \mathrm{C}$. The frequency of Tylhis3AI transposition is the number of $\mathrm{His}^{+} \mathrm{Ura}^{+}$colonies divided by the total number of $\mathrm{Ura}^{+}$colonies plated.

\section{ChIP}

ChIPs were performed essentially as described previously. Yeast strains were grown to $\mathrm{OD}_{600}=0.5$ either in YPDA or CSM minimum media at $30^{\circ} \mathrm{C}$, and cross-linked for $20 \mathrm{~min}$ by the addition of formaldehyde to a final concentration of $1.2 \%$. The crosslinking reaction was quenched by adding glycine at $0.3 \mathrm{M}$ final. Chromatin was sonicated to obtain 400-500 nt of DNA fragment, and $150 \mu \mathrm{L}$ (at $1.25 \mu \mathrm{g} / \mu \mathrm{L}$ ) of sonicated chromatin was immunoprecipitated overnight in the presence of specific antibodies against the N-terminal domain of Rpb1 (Y80, Santa Cruz Biotechnologies), the HA epitope (fp7, Santa Cruz Biotechnologies) for the TBP HA-tagged strain. Immunoprecipitated chromatin was purified with $5 \mathrm{mg}$ of protein A-Sepharose (Amersham Pharmacia). All immunoprecipitations were repeated at least twice with different chromatin extracts. Immunoprecipitated DNA was quantified by real-time PCR using the LightCycler 480 (Roche), with primer pairs available upon request. Signals are expressed as the percentage of input DNA relative to the tf(GAA)P2 (tRNA region in ChrXVI, coordinates 622628622537). Error bars correspond to standard deviations.

\section{Acknowledgments}

We thank L. Bénard for purified recombinant Xrn1, and A. Johnson, A. Culbertson, G. Chanfreau, D. Libri, B. Séraphin, V. Géli, M.J. Curcio, and D. Garfinkel for kindly providing strains and plasmids. We gratefully thank J. Mellor for constant support and encouragement, allowing this study to initiate, and $\mathrm{H}$. Lehir, D. Libri, J. O'Sullivan, B. Séraphin, F. Stutz, and E. Van Dijk for helpful discussions. Special thanks to Sylvie Carmet for editorial assistance and Lucile Astorgues-Xéri and Violaine St Andrée for technical assistance. Our financial support is from ARC, FRM, ATIP-CNRS, and HFSPO.

\section{References}

Aravind, L., Watanabe, H., Lipman, D.J., and Koonin, E.V. 2000. Lineage-specific loss and divergence of functionally linked genes in eukaryotes. Proc. Nat1. Acad. Sci. 97: 11319-11324.
Baur, M., Esch, R.K., and Errede, B. 1997. Cooperative binding interactions required for function of the Tyl sterile responsive element. Mol. Cell. Biol. 17: 4330-4337.

Beliakova-Bethell, N., Beckham, C., Giddings Jr., T.H., Winey, M., Parker, R., and Sandmeyer, S. 2006. Virus-like particles of the Ty3 retrotransposon assemble in association with Pbody components. RNA 12: 94-101.

Bernstein, B.E., Tong, J.K., and Schreiber, S.L. 2000. Genomewide studies of histone deacetylase function in yeast. Proc. Natl. Acad. Sci. 97: 13708-13713.

Bitterman, K.J., Anderson, R.M., Cohen, H.Y., Latorre-Esteves, M., and Sinclair, D.A. 2002. Inhibition of silencing and accelerated aging by nicotinamide, a putative negative regulator of yeast sir2 and human SIRT1. J. Biol. Chem. 277: 45099-45107.

Buhler, M., Haas, W., Gygi, S.P., and Moazed, D. 2007. RNAidependent and -independent RNA turnover mechanisms contribute to heterochromatic gene silencing. Cell 129: 707721.

Capy, P. 2005. Classification and nomenclature of retrotransposable elements. Cytogenet. Genome Res. 110: 457-461.

Coller, J. and Parker, R. 2004. Eukaryotic mRNA decapping. Annu. Rev. Biochem. 73: 861-890.

Curcio, M.J. and Garfinkel, D.J. 1991. Single-step selection for Tyl element retrotransposition. Proc. Natl. Acad. Sci. 88: 936-940.

Dahlberg, J. and Lund, E. 2005. tRNA turnaround. Mol. Cell 19: 292-294.

Danin-Kreiselman, M., Lee, C.Y., and Chanfreau, G. 2003. RNAse III-mediated degradation of unspliced pre-mRNAs and lariat introns. Mol. Cell 11: 1279-1289.

Daugeron, M.C., Mauxion, F., and Seraphin, B. 2001. The yeast POP2 gene encodes a nuclease involved in mRNA deadenylation. Nucleic Acids Res. 29: 2448-2455.

Dehe, P.M. and Geli, V. 2006. The multiple faces of Set1. Biochem. Cell Biol. 84: 536-548.

Dehe, P.M., Pamblanco, M., Luciano, P., Lebrun, R., Moinier, D., Sendra, R., Verreault, A., Tordera, V., and Geli, V. 2005. Histone H3 lysine 4 mono-methylation does not require ubiquitination of histone H2B. J. Mol. Biol. 353: 477-484.

Doma, M.K. and Parker, R. 2006. Endonucleolytic cleavage of eukaryotic mRNAs with stalls in translation elongation. $\mathrm{Na}$ ture 440: 561-564.

Grishok, A., Sinskey, J.L., and Sharp, P.A. 2005. Transcriptional silencing of a transgene by RNAi in the soma of C. elegans. Genes \& Dev. 19: 683-696.

Hickman, M.A. and Rusche, L.N. 2007. Substitution as a mechanism for genetic robustness: The duplicated deacetylases Hst1p and Sir2p in Saccharomyces cerevisiae. PLoS Genet. 3: e126. doi: 10.1371/journal.pgen.0030126.

Hongay, C.F., Grisafi, P.L., Galitski, T., and Fink, G.R. 2006. Antisense transcription controls cell fate in Saccharomyces cerevisiae. Cell 127: 735-745.

Jiang, Y.W. 2002. Transcriptional cosuppression of yeast Ty1 retrotransposons. Genes \& Dev. 16: 467-478.

Jorgensen, R.A. 1995. Cosuppression, flower color patterns, and metastable gene expression states. Science 268: 686-691.

Katan-Khaykovich, Y. and Struhl, K. 2005. Heterochromatin formation involves changes in histone modifications over multiple cell generations. EMBO J. 24: 2138-2149.

Kufel, J., Bousquet-Antonelli, C., Beggs, J.D., and Tollervey, D. 2004. Nuclear pre-mRNA decapping and 5 ' degradation in yeast require the Lsm2-8p complex. Mol. Cell. Biol. 24: 9646-9657.

Kuras, L. and Struhl, K. 1999. Binding of TBP to promoters in vivo is stimulated by activators and requires Pol II holoen- 
zyme. Nature 399: 609-613.

LaCava, J., Houseley, J., Saveanu, C., Petfalski, E., Thompson, E., Jacquier, A., and Tollervey, D. 2005. RNA degradation by the exosome is promoted by a nuclear polyadenylation complex. Cell 121: 713-724.

Laloux, I., Jacobs, E., and Dubois, E. 1994. Involvement of SRE element of Ty1 transposon in TEC1-dependent transcriptional activation. Nucleic Acids Res. 22: 999-1005.

Lander, E.S., Linton, L.M., Birren, B., Nusbaum, C., Zody, M.C., Baldwin, J., Devon, K., Dewar, K., Doyle, M., FitzHugh, W., et al. 2001. Initial sequencing and analysis of the human genome. Nature 409: 860-921.

Longtine, M.S., McKenzie III, A., Demarini, D.J., Shah, N.G., Wach, A., Brachat, A., Philippsen, P., and Pringle, J.R. 1998. Additional modules for versatile and economical PCR-based gene deletion and modification in Saccharomyces cerevisiae. Yeast 14: $953-961$.

Martens, J.A., Wu, P.Y., and Winston, F. 2005. Regulation of an intergenic transcript controls adjacent gene transcription in Saccharomyces cerevisiae. Genes \& Dev. 19: 2695-2704.

Masui, O. and Heard, E. 2006. RNA and protein actors in Xchromosome inactivation. Cold Spring Harb. Symp. Quant. Biol. 71: 419-428.

Mellor, J. 2006. It takes a PHD to read the histone code. Cell 126: $22-24$.

Morillon, A., Springer, M., and Lesage, P. 2000. Activation of the Kss1 invasive-filamentous growth pathway induces Ty1 transcription and retrotransposition in Saccharomyces cerevisiae. Mol. Cell. Biol. 20: 5766-5776.

Morillon, A., Benard, L., Springer, M., and Lesage, P. 2002. Differential effects of chromatin and Gen 4 on the 50-fold range of expression among individual yeast Tyl retrotransposons. Mol. Cell. Biol. 22: 2078-2088.

Muhlrad, D. and Parker, R. 1994. Premature translational termination triggers mRNA decapping. Nature 370: 578-581.

Muhlrad, D., Decker, C.J., and Parker, R. 1995. Turnover mechanisms of the stable yeast PGK1 mRNA. Mol. Cell. Biol. 15: 2145-2156.

Nicolas, E., Yamada, T., Cam, H.P., Fitzgerald, P.C., Kobayashi, R., and Grewal, S.I. 2007. Distinct roles of HDAC complexes in promoter silencing, antisense suppression and DNA damage protection. Nat. Struct. Mol. Biol. 14: 372-380.

Nislow, C., Ray, E., and Pillus, L. 1997. SET1, a yeast member of the trithorax family, functions in transcriptional silencing and diverse cellular processes. Mol. Biol. Cell 8: 2421-2436.

O'Donnell, K.A. and Boeke, J.D. 2007. Mighty Piwis defend the germline against genome intruders. Cell 129: 37-44.

Rinn, J.L., Kertesz, M., Wang, J.K., Squazzo, S.L., Xu, X., Brugmann, S.A., Goodnough, L.H., Helms, J.A., Farnham, P.J., Segal, E., et al. 2007. Functional demarcation of active and silent chromatin domains in human HOX loci by noncoding RNAs. Cell 129: 1311-1323.

Robert, V.J., Sijen, T., van Wolfswinkel, J., and Plasterk, R.H. 2005. Chromatin and RNAi factors protect the C. elegans germline against repetitive sequences. Genes \& Dev. 19: 782-787.

Roguev, A., Schaft, D., Shevchenko, A., Pijnappel, W.W., Wilm, M., Aasland, R., and Stewart, A.F. 2001. The Saccharomyces cerevisiae Set 1 complex includes an Ash2 homologue and methylates histone 3 lysine 4. EMBO J. 20: 7137-7148.

Rundlett, S.E., Carmen, A.A., Kobayashi, R., Bavykin, S., Turner, B.M., and Grunstein, M. 1996. HDA1 and RPD3 are members of distinct yeast histone deacetylase complexes that regulate silencing and transcription. Proc. Natl. Acad. Sci. 93: 14503-14508.

Santos-Rosa, H., Schneider, R., Bannister, A.J., Sherriff, J., Bern- stein, B.E., Emre, N.C., Schreiber, S.L., Mellor, J., and Kouzarides, T. 2002. Active genes are tri-methylated at K4 of histone H3. Nature 419: 407-411.

Santos-Rosa, H., Bannister, A.J., Dehe, P.M., Geli, V., and Kouzarides, T. 2004. Methylation of H3 lysine 4 at euchromatin promotes Sir3p association with heterochromatin. $J$. Biol. Chem. 279: 47506-47512.

Shahbazian, M., Zhang, K., and Grunstein, M. 2005. Histone H2B ubiquitylation controls processive methylation but not monomethylation by Dot1 and Set1. Mol. Cell 19: 271-277.

Shore, D., Squire, M., and Nasmyth, K.A. 1984. Characterization of two genes required for the position-effect control of yeast mating-type genes. EMBO J. 3: 2817-2823.

Sims III, R.J. and Reinberg, D. 2006. Histone H3 Lys 4 methylation: Caught in a bind? Genes \& Dev. 20: 2779-2786.

Struhl, K. 2007. Transcriptional noise and the fidelity of initiation by RNA polymerase II. Nat. Struct. Mol. Biol. 14: 103105.

Sun, Z.W. and Allis, C.D. 2002. Ubiquitination of histone H2B regulates $\mathrm{H} 3$ methylation and gene silencing in yeast. $\mathrm{Na}$ ture 418: 104-108.

Svejstrup, J.Q. 2004. The RNA polymerase II transcription cycle: Cycling through chromatin. Biochim. Biophys. Acta 1677: 64-73.

Thompson, D.M. and Parker, R. 2007. Cytoplasmic decay of intergenic transcripts in Saccharomyces cerevisiae. Mol. Cell. Biol. 27: 92-101.

Uhler, J.P., Hertel, C., and Svejstrup, J.Q. 2007. A role for noncoding transcription in activation of the yeast PHO5 gene. Proc. Natl. Acad. Sci. 104: 8011-8016.

Vagin, V.V., Sigova, A., Li, C., Seitz, H., Gvozdev, V., and Zamore, P.D. 2006. A distinct small RNA pathway silences selfish genetic elements in the germline. Science 313: 320324.

Vanacova, S., Wolf, J., Martin, G., Blank, D., Dettwiler, S., Friedlein, A., Langen, H., Keith, G., and Keller, W. 2005. A new yeast poly(A) polymerase complex involved in RNA quality control. PLOS Biol. 3: e189. doi: 10.1371/journal. pbio.0030189.

van Leeuwen, F., Gafken, P.R., and Gottschling, D.E. 2002. Dot $1 p$ modulates silencing in yeast by methylation of the nucleosome core. Cell 109: 745-756.

Weiner, A.M. 2002. SINEs and LINEs: The art of biting the hand that feeds you. Curr. Opin. Cell Biol. 14: 343-350.

Wyers, F., Rougemaille, M., Badis, G., Rousselle, J.C., Dufour, M.E., Boulay, J., Regnault, B., Devaux, F., Namane, A., Seraphin, B., et al. 2005. Cryptic pol II transcripts are degraded by a nuclear quality control pathway involving a new poly(A) polymerase. Cell 121: 725-737.

Zhang, K., Lin, W., Latham, J.A., Riefler, G.M., Schumacher, J.M., Chan, C., Tatchell, K., Hawke, D.H., Kobayashi, R., and Dent, S.Y. 2005. The Set1 methyltransferase opposes Ipll aurora kinase functions in chromosome segregation. Cell 122: $723-734$ 


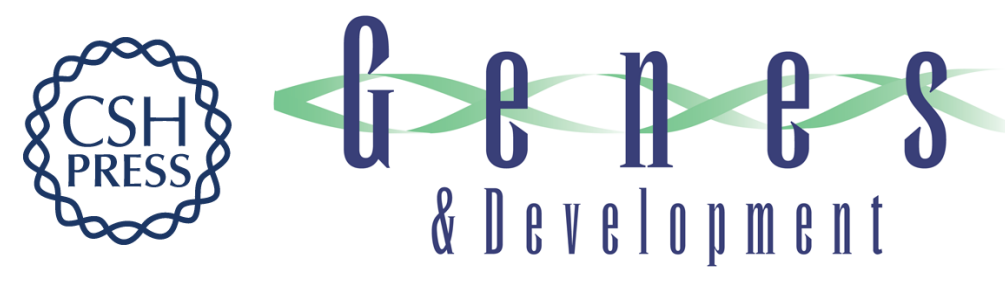

\section{A cryptic unstable transcript mediates transcriptional trans-silencing of the Ty1 retrotransposon in S. cerevisiae}

Julia Berretta, Marina Pinskaya and Antonin Morillon

Genes Dev. 2008, 22:

Access the most recent version at doi:10.1101/gad.458008

Supplemental http://genesdev.cshlp.org/content/suppl/2008/02/19/22.5.615.DC1
Material

References This article cites 57 articles, 24 of which can be accessed free at: http://genesdev.cshlp.org/content/22/5/615.full.html\#ref-list-1

License

Email Alerting

Receive free email alerts when new articles cite this article - sign up in the box at the top Service right corner of the article or click here.

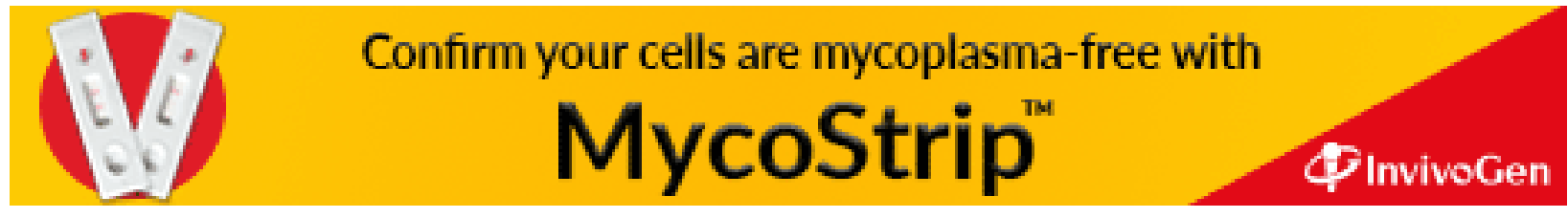

